\title{
Perspectives on the Attitudes of Healthcare Professionals toward Diabetes in Community Health Settings in United Arab Emirates
}

\author{
Wegdan Bani-issa ${ }^{*}$, Kamal Eldeirawi², Hanan Al Tawil ${ }^{1}$ \\ ${ }^{1}$ Department of Nursing, College of Health Sciences, University of Sharjah, Sharjah, United Arab Emirates \\ ${ }^{2}$ Department of Health Systems Science, College of Nursing, University of Illinois at Chicago, Chicago, Illinois, \\ USA \\ Email: ww waniissa@sharjah.ac.ae, keldei1@uic.edu, altawil@sharjah.ac.ae
}

Received 8 November 2014; revised 5 December 2014; accepted 15 December 2014

Academic Editor: Fida Al Momani, Jordan University of Science and Technology, Jordan

Copyright (C) 2015 by authors and Scientific Research Publishing Inc.

This work is licensed under the Creative Commons Attribution International License (CC BY). http://creativecommons.org/licenses/by/4.0/

(c) $\underset{\mathrm{EY}}{\mathrm{B}}$ Open Access

\section{Abstract}

Background: Diabetes is a chronic disease that is associated with high cost and health care utilization. Attitudes of healthcare professionals (HCPs) toward diabetes have a significant impact on quality of diabetes care. Although the prevalence of diabetes in the Arabian Gulf region is alarming, little is known about attitudes of HCPs toward the disease. Methods: This study evaluates the attitudes of 337 HCPs toward diabetes in United Arab Emirates (UAE) including physicians, pharmacists, nurses and dietitians using the Diabetes Attitudes Scale (DAS-3). Data were analyzed descriptively and one way analysis of variance (ANOVA) was used for comparative analyses. Overall, HCPs groups demonstrated relatively adequate attitudes toward diabetes (mean $=3.80, S D=0.45$ ). $\mathrm{Re}$ sults: The highest score reported by HCPs groups was on the need for special training subscale (M $=4.49, \mathrm{SD}=0.38$ ) and the lowest score was seen on patient autonomy subscale $(\mathrm{M}=3.31, \mathrm{SD}=$ 0.45). Physicians showed significantly higher positive attitudes on need for special training, seriousness of diabetes, value of tight glycemic control, and psychosocial aspects of diabetes than other HCPs groups (P values < 0.005); whereas nurses scored the highest on patient autonomy subscale. Pharmacists demonstrated the lowest negative attitudes among HCPs groups on all diabetes attitudes subscales. Conclusions: We recommend conducting more continuing education programs (CEPs) on diabetes care in the UAE, with greater emphasis on patient autonomy. An interdisciplinary approach that is patients' centered is needed to provide efficient diabetes care.

\footnotetext{
${ }^{*}$ Corresponding author.
}

How to cite this paper: Bani-issa, W., Eldeirawi, K. and Al Tawil, H. (2015) Perspectives on the Attitudes of Healthcare Professionals toward Diabetes in Community Health Settings in United Arab Emirates. Journal of Diabetes Mellitus, 5, 1-11. http://dx.doi.org/10.4236/jdm.2015.51001 


\section{Keywords}

\section{Diabetes Attitudes, Healthcare Professionals, Nurses, Pharmacists, Physicians, Dietitians, Continuing Education Programs}

\section{Introduction}

Diabetes is one of the fastest growing chronic health conditions in the world [1]. It is estimated that the prevalence of diabetes in adults will increase worldwide from $6.4 \%$ in 2010 to $7.7 \%$ in 2030 [2]. In Arabian Gulf countries, diabetes is a major health problem affecting $23.9 \%, 23.1 \%$, and $22.9 \%$ of the populations of Saudi Arabia, Kuwait and Qatar, respectively, with evidence showing an upward trend in the prevalence of the disease [1]. Similar trends have been observed in the United Arab Emirates (UAE), in which the prevalence of diabetes is very high and continues to increase overtime with an estimated prevalence of 19.3\% [3]. High and increasing rates of diabetes in the UAE and other Gulf countries could be attributed, in part, to the adoption of westernized diet and lack of physical activity that followed the discovery of oil and the subsequent urbanization of those societies. These lifestyle changes also contributed to high rates of obesity and other metabolic related disorders associated with diabetes [4].

Patients with diabetes make a wide range of routine self-care complex decisions involving medication, nutrition, physical activity, blood glucose monitoring, and stress management. Patient adherence to treatment regimens is crucial to control diabetes and its complications. The high prevalence of diabetes in the UAE, the seriousness of the disease, the high cost and complexity of diabetes care and management mandate a good understanding of factors that influence patients' adherence to diabetes care and self-management regimens. Healthcare professionals (HCPs) play a vital role in fostering a lasting change in patient behaviors, motivating patients toward adherence to diabetes related regimens and helping them to make proper decisions leading to favorable health outcomes [5] [6]. For example, studies have shown that misconceptions of HCPs about diabetes had a negative impact on quality of care provided to patients with diabetes. Aspects of diabetes care including tight glycemic control and patient autonomy are influenced most by the attitudes of HCPs because these aspects depend on the communication patterns between patients and HCPs [7] [8].

It is widely reported that diabetes complications could be prevented or delayed with proper self-management that is influenced by attitudes of HCPs toward the disease [9]-[11]. There is evidence that HCPs' negative and misguided attitudes toward diabetes screening and management have negative impact on adherence of patients to diabetes related regimens [10]. Gagliardino, et al., (2007) stated that misconceptions of HCPs about diabetes, especially with regards to patient autonomy, seriousness of diabetes, and the value of tight glycemic control; contribute to poor quality of care provided to patients with diabetes [8].

Studies on the attitudes of HCPs toward diabetes have demonstrated different attitude patterns across different parts of the world. For example, Odili and Oparah (2012) used the Diabetes Attitudes Scale (DAS-3) and found that although HCPs (nurses, physicians, pharmacists) in Nigeria were in agreement regarding the benefits of diabetes special training programs for HCPs, significant differences with regards to other attitude subscales were noted among participants with nurses demonstrating low attitudes toward seriousness of diabetes, value of tight glycemic control, and patient autonomy [12]. Whereas, doctors and pharmacists had higher attitudes toward the value of tight glycemic control than nurses. Physicians had greater attitudes about the seriousness of type 2 diabetes than nurses and pharmacists.

In a cross-sectional study in Yemen, Babelgaith et al. (2013) found that nurses and pharmacists demonstrated lower attitudes than physicians with regards to the seriousness of diabetes whereas physicians had higher attitudes toward the value of tight glycemic control followed by nurses and pharmacists [10]. In that study, nurses had lower attitudes on all subscales than physicians and pharmacists and All HCPs surveyed were in agreement regarding the importance of empowering patients toward self-management of diabetes [10].

In a multinational survey to assess attitudes of HCPs toward diabetes in eight countries (France, Germany, United Kingdom (UK), Italy, Netherlands, Spain, Sweden, and United States), it was found that physicians tended to have high attitudes toward seriousness of diabetes and psychosocial impact of the disease [13]. An 
earlier study indicated that diabetes related attitudes of nurses and dieticians in the US were consistently more positive than the attitudes of physicians, especially regarding the seriousness aspects of the disease [14]. Anderson and Donnelly (1990) found that physicians tended to view themselves as in control of diabetes with less appreciation of patients' autonomy unlike nurses and dietitians who valued patients' involvement in decisions related to diabetes [15]. Both studies underscored the importance of interdisciplinary team work in diabetes management and the values of understanding patients' perceptions and emotional status by HCPs to establish therapeutic relationship and enhance patients' coping and emotional well-being [14] [15].

Stansfield, Fitzgerald, Oh, and Gruppen (2007) reported that HCPs underestimated patient autonomy and emotions related to diabetes but overestimated the challenge patients associate with the cost of diabetes [6]. Similar results were noted in a later study in the US which found that HCPs had negative attitudes toward patient ability to handle low blood sugar and the psychosocial aspects of diabetes [16].

Although high rates of diabetes have been reported in the UAE, there is limited research on attitudes of HCPs toward diabetes in the country. Despite the recent emphasis on the need for "interdisciplinary teams and "totalcare management" in which all categories of HCPs must directly coordinate and plan care for diabetic patients [17], many of the existing studies related to attitudes of HCPs toward diabetes were limited to one category of HCPs such as physicians [18], pharmacists [17]-[19] and nurses [20] with little focus on the role of dietitians. Hence, this study attempts to assess attitudes of all HCPs related to diabetes and compare those attitudes among subgroups of HCPs. Results of this study will assist in guiding the development of interventions and programs to ensure that HCPs have the necessary training and appropriate attitudes to be able to provide better diabetes care.

\section{Methods}

\subsection{Design and Sample}

This cross-sectional study was conducted with a convenience sample 337 HCPs working in community healthcare settings in the UAE. For this study, all physicians, nurses, pharmacists and dietitians working at primary healthcare centers, outpatients' clinics and community-based pharmacies in Northern Emirates of UAE including Dubai, Ajman, Sharjah, and Ras Al khaimah. Four trained research assistants collected data over six months through face-to-face interviews to ensure quality and completeness of data collected. Consent forms were presented and signed by participants prior to data collection.

Participants were identified through direct visits by the research team to potential study sites where participants were practicing. These sites included primary healthcare centers, outpatients' clinics and communitybased pharmacies in the Northern Emirates. After obtaining the permission of the administration of the sites, the research team approached HCPs and invited them to participate. The study was ethically approved by the ethical committee at the researchers' institution.

This sampling frame was selected because it is less complicated and more economical than random sampling and there is a possibility of polling the desired number of participants in the nearby population [21]. Inclusion criteria included practicing in community based healthcare settings and having at least two years of experience caring for patients with diabetes. Sample size was determined based on the review of previous similar studies [10] [22].

\subsection{Data Collection Instrument}

The Diabetes Attitudes Scale version 3 (DAS-3) was used to assess attitudes of HCPs toward diabetes [9] [22]. The DAS-3 is a self-reported instrument used to assess general scientific knowledge and attitudes of HCPs and patients toward diabetes and diabetes management. The current scale is based on an earlier version which was developed through Delphi method [23]. The new version (DAS 3) was revised by a panel of diabetes experts, including physicians, nurses, dietitians, and patients associated with the University of Michigan Diabetes Research and Training Center [9]. The scale consists of 33 items and includes five discrete subscales assessing HCPs attitudes with regards to diabetes care. Participants responded on a 5-point Likert scale where $1=$ strongly agree, and 5 = strongly disagree. The coding for negatively stated statements was reversed. Higher score indicating more positive attitudes in the examined area of diabetes care. In our study, the English version of DAS-3 was administered to participants because English is the commonly used language by HCPs in the UAEs and participants speak and understand English adequately. 
The scale consists of 33 items and includes five discrete subscales assessing HCPs attitudes with regards to diabetes. The first subscale assesses attitudes toward the need for special training and includes 5 items on communication, patient education, and counseling. For example, one of the statements is: "In general, I believe that health care professionals who treat people with diabetes should be trained to communicate well with their patients.” The second subscale includes 7 items assessing HCPs attitudes toward the seriousness of type 2 diabetes. For example, one statement is: "In general, I believe that people who do not need to take insulin to treat their diabetes have a pretty mild disease.” The third subscale includes 7 items on attitudes toward the value of tight glucose control for the prevention of late complications. For instance, one of the statements is: "In general, I believe that most people can enjoy life and still keep tight blood sugar control.” In the $4^{\text {th }}$ subscale, HCPs respond to 6 items about their attitudes on the psychosocial impact of diabetes such as, one statement is: "In general, I believe that diabetes is hard because you never get a break from it." While the $5^{\text {th }}$ subscale includes 8 item on HCPs attitudes toward encouraging patient autonomy and the need to involve patients in daily decision related to diabetes. For instance, one of the statements is: "In general, I believe that people with diabetes have a right to decide how hard they will work to control their blood sugar.”

The DAS-3 was found to have adequate psychometric properties with internal consistency reliability of Chronbach's alpha ranging from 0.65 for psychosocial impact of diabetes to 0.80 for seriousness of diabetes [9]. Validity of the DAS-3 was supported through consistency of findings with previous DAS surveys and through content validity established by the rigorous new Delphi revision process [9]. Anderson and colleagues (1998) concluded that the DAS-3 is superior to other previous measures of diabetes attitudes, applicable, and suitable for assessing attitudes of patients and HCPs toward diabetes [9].

\subsection{Data Analysis and Procedure}

Statistical analysis was conducted using the Statistical Analysis System (SAS) version 9.3. For descriptive statistics, all study variables were analyzed including percentages and means. Analysis of variance (ANOVA) was used to test difference in mean attitude scores among four HCPs groups and by demographic characteristics as well as other factors (Training and certifications). The significance level was set at $p$ value of less than 0.05 .

\section{Results}

\subsection{Response Rate and Descriptive Statistics}

Of the five hundred potential HCPs who were invited to participate in the study, a total of 337 (67.4\%) completed the survey; 96 physicians (28.5\%), 127 nurses (37.7\%), 62 (18.4\%) pharmacists and 52 (15.4\%) dietitians. Participants came from Northern Emirates of the UAE as follows: Sharjah $(n=160,47.48 \%)$, Dubai $(n=97$, 28.78\%), Ajman ( $n=64,19 \%)$, and Ras Al khaimah ( $n=16,4.74)$.

As shown in Table 1, the age of the participants ranged from 19 to 61 years with physicians being the oldest group followed by nurses while pharmacists were the youngest group. Females represented 70\% of participants; 83\% of nurses, $61.46 \%$ of physicians, and $53.23 \%$ of pharmacists. Years of experiences of participants significantly varied from less than a year $(n=68,20.18 \%)$ to more than 15 years $(n=47,13.95 \%)$. Pharmacists had the least while physicians had the most experience working with patients with diabetes.

Surprisingly, more than half of the participants $(n=179,53.12 \%)$ did not receive any kinds of training by diabetes experts anywhere. Pharmacists were the least likely to had training related to diabetes than the professionals from the other groups while physicians were the most trained group. Further, 78.93\% $(n=266)$ were not certified diabetes educators with more certified physicians than other HCPs (see Table 1).

\subsection{Healthcare Professionals' Attitudes toward Diabetes}

Attitudes toward diabetes were divided into five subscales, as described earlier in the data collection instrument including 1) the need for special training; 2) the seriousness of diabetes; 3) the value of tight glycemic control; 4) the psychosocial impact of diabetes on the patient's life; and 5) and patient autonomy. As shown in Table 2, the mean scores for all subscales was $3.80(\mathrm{SD}=0.45)$. The highest attitude score was on the need for special training subscale $(M=4.50, \mathrm{SD}=0.38)$. Specifically, participants scored higher on items related to the need for training, such as need to be trained to communicate well with patients, taught how daily diabetes care affects pa- 
Table 1. Distribution of demographic data of healthcare professionals per groups $(\mathrm{N}=337)$.

\begin{tabular}{|c|c|c|c|c|c|}
\hline & Physicians ( $n=96$ ) & Dietitians $(n=52)$ & Nurses $(n=127)$ & Pharmacists $(n=62)$ & P-value ${ }^{a}$ \\
\hline \multicolumn{6}{|c|}{ Age group (years) } \\
\hline $19-30$ & 16.67 & 19.23 & 27.56 & 51.61 & $<0.0001$ \\
\hline $31-40$ & 26.04 & 63.46 & 37.01 & 38.71 & \\
\hline $41-61$ & 57.29 & 17.31 & 35.43 & 9.68 & \\
\hline \multicolumn{6}{|l|}{ Gender } \\
\hline Females & 61.46 & 75 & 83.46 & 53.23 & $<0.0001$ \\
\hline Males & 38.54 & 25 & 16.54 & 46.77 & \\
\hline \multicolumn{6}{|l|}{ Nationality } \\
\hline Emirati & 16.67 & 21.15 & 4.72 & 22.58 & 0.0013 \\
\hline Non-Emirati & 83.33 & 78.85 & 95.28 & 77.42 & \\
\hline \multicolumn{6}{|c|}{ Years of experience } \\
\hline$<1$ year & 9.38 & 15.38 & 24.41 & 32.26 & 0.0024 \\
\hline $1-5$ & 32.29 & 25 & 29.92 & 24.19 & \\
\hline $6-10$ & 20.83 & 34.62 & 19.69 & 22.58 & \\
\hline $11-15$ & 16.67 & 19.23 & 9.45 & 16.13 & \\
\hline More than 15 & 20.83 & 5.77 & 16.54 & 4.84 & \\
\hline \multicolumn{6}{|c|}{ Diabetes training } \\
\hline Yes & 64.58 & 42.31 & 48.82 & 19.35 & $<0.0001$ \\
\hline No & 35.42 & 57.69 & 51.18 & 80.65 & \\
\hline \multicolumn{6}{|c|}{ Diabetes certification } \\
\hline Yes & 26.04 & 21.15 & 18.11 & 19.35 & 0.5308 \\
\hline No & 73.96 & 78.85 & 81.89 & 80.65 & \\
\hline
\end{tabular}

abased on Chi square test.

Table 2. Overall diabetes attitudes scores for healthcare professionals $(\mathrm{N}=337)$.

\begin{tabular}{cccc}
\hline Subscale & Number of items & Mean $(\mathrm{M})$ & Standard deviation $( \pm \mathrm{SD})$ \\
\hline Special training & 5 & 4.50 & 0.38 \\
Seriousness of diabetes & 7 & 3.84 & 0.48 \\
Value of tight glycemic control & 7 & 3.50 & 0.43 \\
Psychosocial impact of diabetes & 6 & 3.85 & 0.49 \\
Patient autonomy & 8 & 3.31 & 0.45 \\
Total & 33 & 3.80 & 0.45 \\
\hline
\end{tabular}

tients' lives, learn counseling skills, and set goals for patients and not just tell them what to do. Participants differed significantly in their attitude toward the need for special training with the highest need expressed by physicians followed by dietitians, nurses, and pharmacists $(P=0.005)$ (see Table 3 ).

On the other hand, the lowest attitude score was for the patient autonomy subscale $(\mathrm{M}=3.31$, $\mathrm{SD}=0.45$ ). Specifically, HCPs scored less on items related to patient autonomy such as having persons with diabetes make 
Table 3. Comparison of diabetes attitude score between healthcare professional groups $(\mathrm{N}=337)$.

\begin{tabular}{|c|c|c|c|c|}
\hline Subscale & HCPs category & Mean (M) & Standard deviation $( \pm \mathrm{SD})$ & P value $^{\mathrm{a}}$ \\
\hline \multirow[t]{4}{*}{ Special training } & Physicians & 4.60 & 0.33 & 0.005 \\
\hline & Dietitians & 4.47 & 0.42 & \\
\hline & Nurses & 4.44 & 0.36 & \\
\hline & Pharmacists & 4.41 & 0.44 & \\
\hline \multirow[t]{4}{*}{ Seriousness of diabetes } & Physicians & 4.15 & 0.51 & $<0.0001$ \\
\hline & Dietitians & 3.68 & 0.40 & \\
\hline & Nurses & 3.80 & 0.54 & \\
\hline & Pharmacists & 3.56 & 0.48 & \\
\hline \multirow[t]{4}{*}{ Value of tight glyemic control } & Physicians & 3.68 & 0.46 & $<0.0001$ \\
\hline & Dietitians & 3.48 & 0.43 & \\
\hline & Nurses & 3.51 & 0.43 & \\
\hline & Pharmacists & 3.34 & 0.40 & \\
\hline \multirow[t]{4}{*}{ Psychosocial impact of diabetes } & Physicians & 4.03 & 0.48 & $<0.0001$ \\
\hline & Dietitians & 3.73 & 0.41 & \\
\hline & Nurses & 3.88 & 0.46 & \\
\hline & Pharmacists & 3.63 & 0.50 & \\
\hline \multirow[t]{4}{*}{ Patient autonomy } & Physicians & 3.30 & 0.45 & 0.2438 \\
\hline & Nurses & 3.60 & 0.50 & \\
\hline & Dietitians & 3.34 & 0.40 & \\
\hline & Pharmacists & 3.00 & 0.46 & \\
\hline
\end{tabular}

abased on ANOVA.

important decisions about their care. As shown in Table 3, HCPs did not differ significantly in their attitude score related to patient autonomy with nurses scored the highest $(\mathrm{M}=3.60, \mathrm{SD}=0.50)$ and pharmacists scored the lowest $(\mathrm{M}=3.00, \mathrm{SD}=0.46)$.

The overall mean attitude score toward the value of tight glycemic control was higher than that reported for patient autonomy $(M=3.50, S D=0.43)$. We found significant differences in attitudes toward the value of tight glycemic control for preventing late complications by type of health profession with physicians scoring the highest mean score $(\mathrm{M}=3.68, \mathrm{SD}=0.46)$ and pharmacists scoring the lowest $(\mathrm{M}=3.34, \mathrm{SD}=0.40)$ (See Table 3).

Comparisons among different groups of HCPs revealed significant differences in their attitudes toward the seriousness of diabetes $(\mathrm{P}<0.0001)$ with physicians scoring the highest and pharmacists scoring the lowest. HCPs also varied on their attitude toward the psychosocial impact of diabetes based on their profession $(\mathrm{P}=0.0001)$ with the highest score attained by physicians and the lowest by pharmacists (See Table 3).

Our results indicated that pharmacists had the least favorable attitudes toward diabetes, especially in the domains of patient autonomy and the value of tight glycemic control. Whereas, physicians had the most favorable attitudes toward diabetes on all subscales compared to all HCPs groups, except for patient autonomy where nurses had greater attitudes to patients' involvement in their own diabetes care decisions than other HCPs groups.

Results of our study also indicated that special training by diabetes experts had a positive impact on the attitudes toward diabetes; HCPs who received training by diabetes experts had more desirable attitudes toward diabetes compared to those who did not receive training; as shown in Table 4, significant differences were rec- 
Table 4. Comparison of diabetes attitude scores by training in the area of diabetes $(\mathrm{N}=337)$.

\begin{tabular}{|c|c|c|c|c|}
\hline Subscale & Training & Mean $(M)$ & Standard deviation $( \pm \mathrm{SD})$ & $\mathrm{P}_{\text {value }}{ }^{\mathrm{a}}$ \\
\hline \multirow[t]{2}{*}{ Special training } & NO & 3.72 & 0.46 & 0.014 \\
\hline & Yes & 4.54 & 0.37 & \\
\hline \multirow[t]{2}{*}{ Seriousness of diabetes } & NO & 4.43 & 0.39 & \\
\hline & Yes & 3.93 & 0.57 & 0.004 \\
\hline \multirow[t]{2}{*}{ Value of tight glycemic control } & NO & 3.75 & 0.51 & \\
\hline & Yes & 3.61 & 0.43 & 0.0003 \\
\hline \multirow[t]{2}{*}{ Psychosocial impact of diabetes } & NO & 3.44 & 0.44 & \\
\hline & Yes & 3.92 & 0.51 & 0.01 \\
\hline \multirow[t]{2}{*}{ Patient autonomy } & NO & 3.79 & 0.45 & \\
\hline & Yes & 3.78 & 0.50 & 0.26 \\
\hline
\end{tabular}

abased on ANOVA.

orded on the four subscales including the need for special training, seriousness of diabetes, value of tight glycemic control, and psychosocial impact of diabetes (all P values were less than 0.05). Similarly, HCPs who were certified diabetes educators scored significantly higher than those without certifications on all five diabetes attitudes subscales (all P values were less than 0.05) (See Table 5).

\section{Discussion}

To the best of our knowledge, the current study is the first to assess attitudes of HCPs toward diabetes in the Arabian Gulf region. Unlike previous studies which focused on a particular category of HCPs [17]-[20], the current study is unique as our sample included most categories of HCPs with different specialties and backgrounds.

One of the important findings of our study was the great need for special training expressed by all categories of HCPs. These findings were consistent with those from previous studies in which HCPs requested more diabetes related training [9] [10] [12]. The need for special training by HCPs in our study was slightly higher than that reported in similar investigations utilizing the DAS-3 scale in different countries such as Yemen $(\mathrm{M}=4.2$, $\mathrm{SD}=0.47)$ [10], Argentina $(\mathrm{M}=4.5, \mathrm{SD}=0.35)$ [8] and Nigeria $(\mathrm{M}=4.5, \mathrm{SD}=0.64)$ [12]. Physicians, in our study, scored slightly higher than other groups of HCPs on the need for special training which is consistent with scores attained by physicians in the USA $(\mathrm{M}=4.66, \mathrm{SD}=0.36)$ [24]. Yet, in other studies, other HCPs groups (allied providers, nurse practitioners, nurses, physicians assistants) scored higher than physicians [25].

Our findings suggest that HCPs in the UAE understand the burdens and complexity of diabetes as well as their own shortfall in handling a wide range of clinical, psychosocial, and financial issues associated with the management of diabetes. Therefore, the UAE health government should target all categories of HCPs in continuing education programs (CEPs). This is supported by our findings and those of others demonstrating the positive impact of special training on attitudes of HCPs related to diabetes care [8] [12] [25].

With regards to the seriousness of diabetes, results indicated that physicians perceived diabetes as a serious disease more than other HCPs groups $(\mathrm{M}=4.15, \mathrm{SD}=0.51)$ which is in agreement with finding from other studies [12]. Yet, unlike our results, physicians were more likely to underestimate the seriousness of diabetes than other categories of HCPs in some other studies [13].

For the psychosocial impact subscale, scores attained in our study were lower than those reported by the study of Odili and Oparah (2012) $(\mathrm{M}=4.07, \mathrm{SD}=0.93)$ and higher than the findings obtained in the study by Babelgaith et al. (2012) $(\mathrm{M}=3.7, \mathrm{SD}=0.42)$ [10] [12]. Consistent with our findings, other studies found that physicians scored the highest among all HCPs groups on the psychosocial aspects of diabetes [10] [12] [13].

The findings regarding the seriousness of diabetes and psychosocial impact of diabetes in patients were expected as most CEPs related to diabetes focus on clinical guidelines, biological, pathophysiological, psychosocial, and aggressive treatment to prevent late complications aspects of disease [12] [24]. Although little data are 
Table 5. Comparison of diabetes attitude score by diabetes certification $(\mathrm{N}=337)$.

\begin{tabular}{|c|c|c|c|c|}
\hline Subscale & Certification & Mean (M) & Standard deviation $( \pm \mathrm{SD})$ & $\mathrm{P}_{\text {value }}{ }^{\mathrm{a}}$ \\
\hline \multirow[t]{2}{*}{ Special training } & NO & 3.67 & 0.46 & 0.0022 \\
\hline & Yes & 4.60 & 0.34 & \\
\hline \multirow[t]{2}{*}{ Seriousness of diabetes } & NO & 4.45 & 0.38 & \\
\hline & Yes & 4.04 & 0.57 & 0.0006 \\
\hline \multirow[t]{2}{*}{ Value of tight glycemic control } & NO & 3.787 & 0.53 & \\
\hline & Yes & 3.70 & 0.42 & $<0.0001$ \\
\hline \multirow[t]{2}{*}{ Psychosocial impact of diabetes } & NO & 3.47 & 0.44 & \\
\hline & Yes & 4.10 & 0.454 & $<0.0001$ \\
\hline \multirow[t]{2}{*}{ Patient autonomy } & NO & 3.78 & 0.47 & \\
\hline & Yes & 4.04 & 0.43 & $<0.0001$ \\
\hline
\end{tabular}

abased on ANOVA.

available on the nature of diabetes education in UAE, it is known that most CEPs attract physicians more than other HCPs groups. This might explain the highest score reported by physicians on the seriousness of diabetes and the psychosocial impact of diabetes. HCPs from all professions, and not only medicine, should be required to participate in CEPs related to diabetes to improve their attitudes toward diabetes care and management. This is especially important as more health care entities move to the interdisciplinary approach in improving diabetes control and management [8].

Results of our study indicated that nurses had the highest positive attitude on patient autonomy subscale followed by dietitians, pharmacists and physicians. Nurses in our study believe that diabetic patients should be given the choice and greater autonomy in care related decisions. This is consistent with findings from the studies [6] [16]. Researchers agree that nurses are more committed to helping patients through her supportive educational role and are valuing patients' involvement in care related decisions more than physicians who view themselves as in control of diabetes and trained to make decisions for patients [12] [14] [15] [26]. Hajos et al. (2011) highlighted the need for patient involvement and shared decision making in diabetes care as suggested by their findings showing that patients seek active involvement in daily decisions related to diabetes [13].

Importantly, we found that the overall score on patients autonomy subscale was the lowest of all the attitude subscales $(\mathrm{M}=3.31$, SD = 0.45). This observation is consistent with results from prior studies [6] [10] [12] [13] [19]. The lowest score was reported by Gagliardino’s et al. (2007) study where HCPS scored 2.79 on patient autonomy using the DAS-3 scale [8]. Odili and Oparah (2012) attributed the low score on patient autonomy subscale observed in their study to the fact that all HCPs do not feel that patients are knowledgeable enough about the disease to make decisions [12].

Support for patients' autonomy and involvement in their own diabetes management decisions and collaboration with HCPs was found to be the strongest predictor of patient-reported outcomes as indicated by the worldwide Diabetes Attitudes, Wishes, and Needs (DAWN) study involving 3170 patients with type 2 diabetes [27]. Therefore, CEPs need to boost HCPs attitudes toward patient autonomy to assist patient make informed choices about their care plans and daily self-care of diabetes [12]. It is important that CEPs include specific sessions on the importance of empowering patients and involving them in the decision making process related to diabetes.

For the fifth subscale of the values of tight glycemic control, all HCPs scored higher than their score on patient autonomy $(\mathrm{M}=3.50, \mathrm{SD}=0.43)$ with physicians scored the highest and pharmacists scored the lowest. These results are almost consistent with findings from others study $(\mathrm{M}=3.3, \mathrm{SD}=0.67)$ [10]. In other studies, nurses showed the most significant negative attitudes toward the value of tight glycemic control than physicians and pharmacists [10] [12]. Pharmacists in our study scored less than physicians on the attitudes toward the value of tight glycemic control unlike what was found in other [10] [12] [19]. As the value of tight glycemic control is very important to prevent diabetes complications (UK Perspective Diabetes Study, 1989), the attitudes of HCPs toward tight glycemic control should be improved to ensure proper management of the disease [28]. 
It was evident in our study that training has a significant impact on diabetes attitude subscale, except for autonomy. Therefore, it is important that HCPs receive adequate training on diabetes care. It is important that diabetes training programs should be expanded to include not only the biological content of diabetes, but should integrate concepts of patient autonomy and empowerment to be involved in all health related decisions to successfully perform desired self management activities [24] [29]. The American Diabetes Association (ADA) (2014) advocates that people with diabetes must assume an active role in their care [30]. Patient autonomy needs to be integrated earlier in educational preparation of all healthcare specialties prior to clinical practice to provide a more successful approach that is patient-centered and interdisciplinary for diabetic patients [12].

Our results indicated that there is a great need for certification in the area of diabetes in UAE. Diabetes certification is important as it was found to influence significantly attitudes toward diabetes [12]. It is common that only nurses are certified diabetes educators (CDEs), but it is important that pharmacists and dietitians should also be CDEs to provide the best care possible for diabetic patients.

\section{Conclusion}

This study was a preliminary effort to understand the attitudes of HCPs toward diabetes in UAE. The inclusion of all categories of HCPs adds value to our study. The addition of dietitian represents a strength since they are less likely to be included in similar studies. Further studies are needed to explore the interventions needed for achieving clinically significant attitude changes. Our study was a cross sectional study and included HCPs from Northern Emirates only of UAE. Future studies should include larger samples from other Emirates and countries to allow for comparisons across different Arabian gulf countries. Perspectives of patients on aspects of diabetes care need to be examined and compared with those of HCPs to determine areas for improvement for better health outcomes. As a strong theoretical support and correlational evidence exist for the attitude-behavior relationship, future research should focus on behavioral outcomes to validate the use of HCPs attitudes as a proxy for the real behavior change. Improving HCPs attitudes is important, yet it is not the only factor that impacts care for diabetic patients. CEPs should assist in translating these attitudes into the quality of healthcare. Our study assessed HCPs attitudes and indicated that CEPs are needed by all groups of HCPs to change the attitudes and subsequently their behaviors toward diabetes. There is an urgent need for interdisciplinary work that is geared toward boosting patient autonomy to empower them toward diabetes related decisions.

\section{Acknowledgements}

The authors gratefully acknowledge research assistants from the nursing program for their contribution to the data collection process. We wish also to acknowledge healthcare providers for participation in this study.

\section{Conflict of Interest}

The authors declare that there is no conflict of interest that could be perceived as prejudicing the impartiality of the research. We fully declare that no financial or other potential conflict of interest.

\section{References}

[1] International Diabetes Federation (2013) Diabetes Atlas (6th Edition). http://www.idf.org/diabetesatlas

[2] Sicree, R., Shaw, J. and Zimmet, P. (2013) The Global Burden Diabetes and Impaired Glucose Tolerance. https://www.idf.org/sites/default/files/The_Global_Burden.pdf

[3] Bulletin of the World Health Organization (2013) The Weight of Affluence. http://www.who.int/bulletin/volumes/88/2/10-020210/en/

[4] Wen Ng, Sh., Zaghloul, S., Ali, H., Harrison, G., Yeatts, K., Sadig, M. and Popkin, B. (2011) Nutrition Transition in the United Arab Emirates (UAE). European Journal of Clinical Nutrition, 65, 1328-1337. http://dx.doi.org/10.1038/ejcn.2011.135

[5] Atak, N., Gurkan, T. and Kose, K. (2008) The Effect of Education on Knowledge, Self Management Behaviours and Self Efficacy of Patients with Type 2 Diabetes. Australian Journal of Advanced Nursing, 26, 66-74 (32 ref.).

[6] Stansfield, R.B., Fitzgerald, J.T., Oh, M. and Gruppen, L. (2007) Where Patients and Providers Don't See Eye-to-Eye: How Attitudes Differ about Different Aspects of Diabetes. Diabetes, Supp. 1, pA506.

[7] Anderson, R.M., Fitzgerald, J.T. and Oh, M.S. (1993) The Relationship between Diabetes-Related Attitudes and Pa- 
tients’ Self-Reported Adherence. Diabetes Educator, 19, 287-292. http://dx.doi.org/10.1177/014572179301900407

[8] Gagliardino, J.J., González, C. and Caporale, J.E. (2007) The Diabetes-Related Attitudes of Health Care Professionals and Persons with Diabetes in Argentina. American Journal of Public Health, 22, 304-307.

[9] Anderson, R.M., Fitzgerald, J.T., Funnell. M.M. and Gruppen, L.D. (1998) The Third Version of the Diabetes Attitude Scale. Diabetes Care, 21, 1403-1407. http://dx.doi.org/10.2337/diacare.21.9.1403

[10] Babelgaith. S., Alfadly, S. and Baidi, M. (2013) Assessment of the Attitude of Health Care Professionals towards Diabetes Care in Mukalla, Yemen. International Journal of Public Health Science, 2, 159-164

[11] Daly, J.M., Hartz, A.J., Xu, Y., Levy, B.T., James, P.A., Merchant, M.L. and Garrett, R.E. (2009) An Assessment of Attitudes, Behaviors, and Outcomes of Patients with Type 2 Diabetes. Journal of the American Board of Family Medicine, 22, 280-290. http://dx.doi.org/10.3122/jabfm.2009.03.080114

[12] Odili, V.U. and Oparah, A.C. (2012) Attitudes of Health Care Professionals toward Diabetes. West African Journal of Pharmacy, 23, 54-59.

[13] Hajos, T.R., Polonsky, W.H., Twisk, J.W., Dain, M.P. and Snoek, F.J. (2011) Do Physicians Understand Type 2 Diabetes Patients' Perceptions of Seriousness; the Emotional Impact and Needs for Care Improvement? A Cross-National Survey. Patient Education and Counseling, 85, 258-263. http://dx.doi.org/10.1016/j.pec.2010.08.019

[14] Anderson, R.M., Donnelly, M.B., Dedrick, R.F. and Gressard, C.P. (1991) The Attitudes of Nurses, Dietitians, and Physicians toward Diabetes. Diabetes Education, 17, 261-268. http://dx.doi.org/10.1177/014572179101700407

[15] Anderson, R.M. and Donnelly, M.B. (1990) Words and Meaning: A Cautionary Tale for Diabetes Educators. Diabetes Education, 16, 117-122. http://dx.doi.org/10.1177/014572179001600208

[16] Fitzgerald, J.T., Stansfield, R.B., Tang, T., Oh, M., Frohna, A., Armbruster, B., Gruppen, L. and Anderson, R. (2008) Patient and Provider Perceptions of Diabetes: Measuring and Evaluating Differences. Patient Education and Counseling, 70, 118-125. http://dx.doi.org/10.1016/j.pec.2007.09.005

[17] Bisheya, A.F., El-Mijbri, S.A., Beshyah, S.A. and Sherif, I.H. (2011) Community Pharmacists’ Knowledge, Attitudes and Practices in Diabetes Care in Tripoli, Libya. Ibnosina Journal of Medicine and Biomedical Sciences, 3, 89-95.

[18] Suraci, C., Mulas, F., Rossi, M.C., Gentile, S. and Giorda, C.B. (2012) Management of Newly Diagnosed Patients with Type 2 Diabetes: What Are the Attitudes of Physicians? A SUBITO! AMD Survey on the Early Diabetes Treatment in Italy. Acta Diabetologica, 49, 429-433. http://dx.doi.org/10.1007/s00592-012-0374-5

[19] Chen, H.Y., Lee, T.Y., Huang, W.T., Chang, C.J. and Chen, C.M. (2004) The Short-Term Impact of a Continuing Education Program on Pharmacists' Knowledge and Attitudes toward Diabetes. American Journal of Pharmaceutical Education, 68, 1-6. http://dx.doi.org/10.5688/aj6805121

[20] Livingston, R. and Dunning, A.M. (2010) Practice Nurses’ Role and Knowledge about Diabetes Management within Rural and Remote Australian General Practices. European Diabetes Nursing, 7, 55-62. http://dx.doi.org/10.1002/edn.158

[21] Grove, S.K., Burns, N. and Gray, J. (2012) The Practice of Nursing Research: Appraisal, Synthesis, and Generation of Evidence. 7th Edition, Saunders, St. Louis. http://dx.doi.org/10.12968/pnur.2012.23.9.444

[22] Fitzgerald, J.T., Davis, W.K., Connell, C.M., Hess G.E., Funnell, M.M. and Hiss, R.G. (1996) Development and Validation of the Diabetes Care Profile. Evaluation and the Health Professions, 19, 208-230. http://dx.doi.org/10.1177/016327879601900205

[23] Anderson, R.M., Donnelly, M.B., Gressard, C.P. and Dedrick, R.F. (1989) Development of Diabetes Attitude Scale for Health-Care Professionals. Diabetes Care, 12, 120-127. http://dx.doi.org/10.2337/diacare.12.2.120

[24] Sharp, L.K. and Lipsky, M.S. (2002) Continuing Medical Education and Attitudes of Health Care Providers toward Treating Diabetes. The Journal of Continuing Education in the Health Professions, 22, 103-112. http://dx.doi.org/10.1002/chp.1340220206

[25] Sharp, L.K. and Lipsky, M.S. (1999) The Short-Term Impact of a Continuing Medical Education Program on Providers' Attitudes toward Treating Diabetes. Diabetes Care, 22, 1929-1932. http://dx.doi.org/10.2337/diacare.22.12.1929

[26] Valentine, V. (2010) Insulin Initiation during a 20-Minute Office Visit: Part 1: Setting the Scene. Diabetes Spectrum, 23, 188-193. http://dx.doi.org/10.2337/diaspect.23.3.188

[27] Peyrot, M., Rubin, R.R., Lauritzen, T., Skovlund, S.E., Snoek, F.J., Matthews, D.R., Landgraf, R. and Kleinebreil, L. (2005) Resistance to Insulin Therapy among Patients and Providers: Results of the Cross-National Diabetes Attitudes, Wishes, and Needs (DAWN) Study. Diabetes Care, 28, 2673-2679. http://dx.doi.org/10.2337/diacare.28.11.2673

[28] UK Prospective Diabetes Study Group (1998) Tight Blood Pressure Control and Risk of Macrovascular and Microvascular Complications in Type 2 Diabetes: UKPDS 38. British Medical Journal, 317, 703-713. http://dx.doi.org/10.1136/bmj.317.7160.713 
[29] Delamater, A.M. (2006) Improving Patient Adherence. Clinical Diabetes, 24, 71-77. http://dx.doi.org/10.2337/diaclin.24.2.71

[30] American Diabetes Association (2014) Standards of Medical Care in Diabetes-2014. Diabetes Care, 37, S14-S80. http://dx.doi.org/10.2337/dc14-S014 
Scientific Research Publishing (SCIRP) is one of the largest Open Access journal publishers. It is currently publishing more than 200 open access, online, peer-reviewed journals covering a wide range of academic disciplines. SCIRP serves the worldwide academic communities and contributes to the progress and application of science with its publication.

Other selected journals from SCIRP are listed as below. Submit your manuscript to us via either submit@scirp.org or Online Submission Portal.
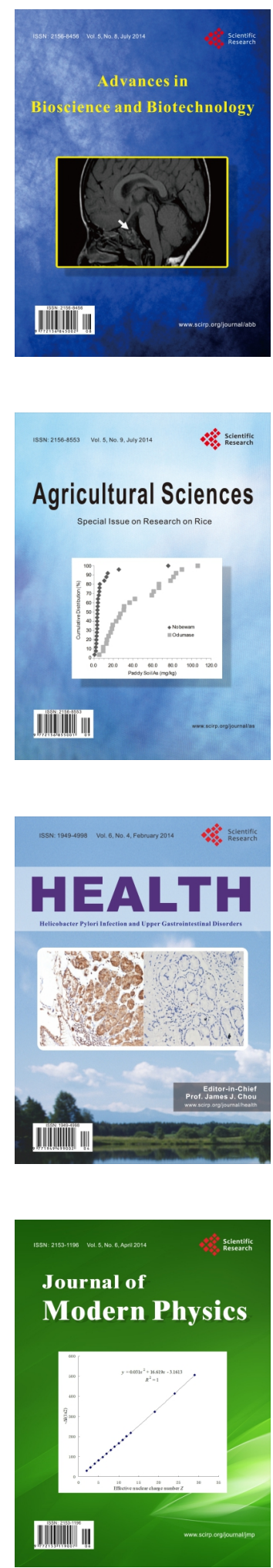
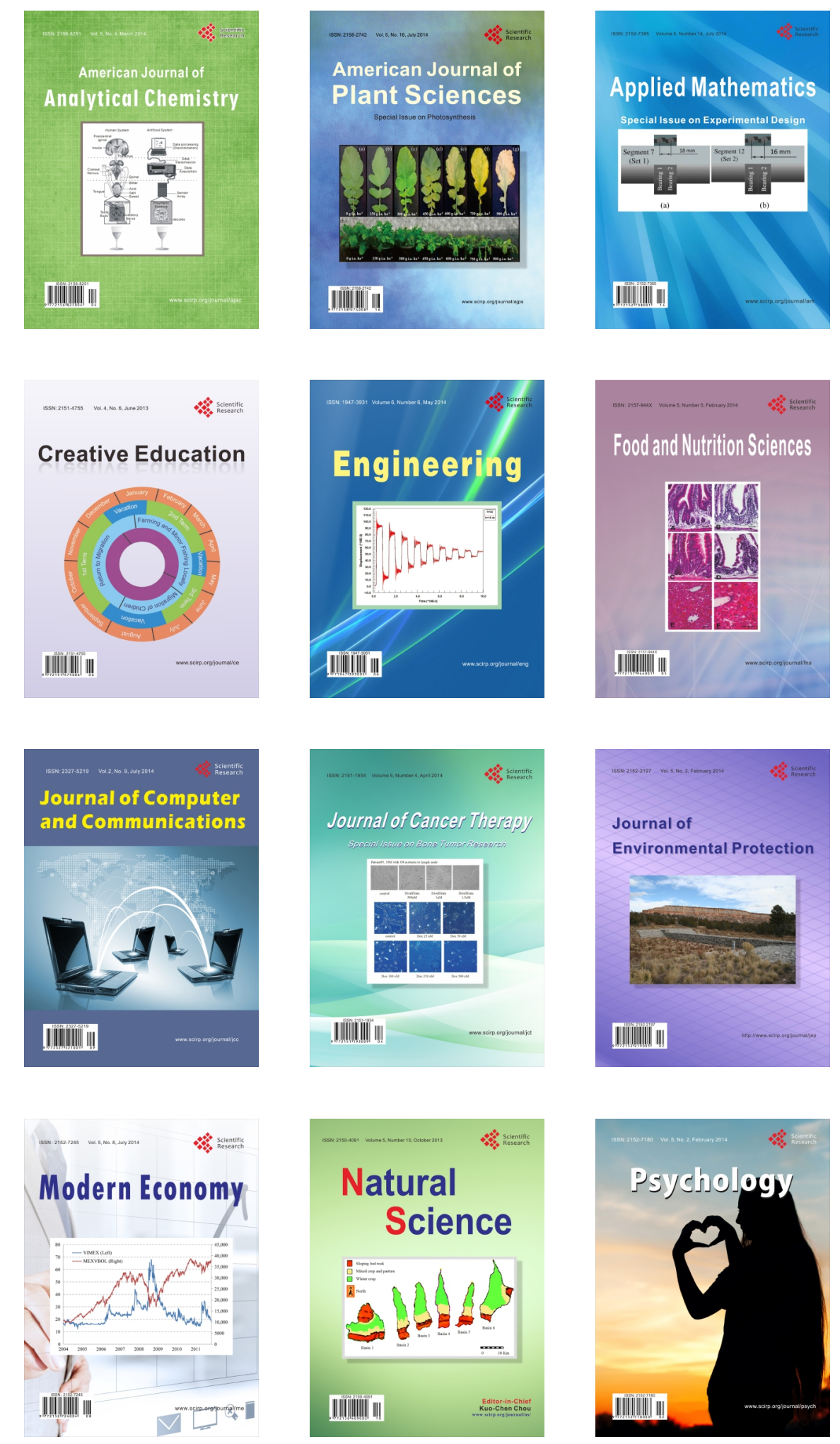